\title{
Evolution and Enlightenment of City Brand Image Design of Seoul, Korea
}

\author{
Yong $\mathrm{Liu}^{1, *}$ \\ ${ }^{1}$ School of Art and Design, Wuhan Textile University, Wuhan, Hubei, China \\ *Corresponding author. Email:2019095@wtu.edu.cn
}

\begin{abstract}
In the process of building city brand strategy, city brand image design is the most intuitive way of expression. This paper studies the context of city brand image design in Seoul, Korea. Firstly, it sorts out the theoretical background through literature research; secondly, it divides the development history of Seoul city brand into three periods, namely "germination period", "growth period" and "maturity period", and makes a comparative analysis; finally, it explains the concepts of Omni-Integrated Marketing and Variable Design Form.
\end{abstract}

Keywords: Seoul, City brand image design, Evolution and enlightenment.

\section{INTRODUCTION}

In the information age, the vast majority of cities have shifted from pure economic competition to cultural "soft power" competition, each constantly making efforts to build a city brand image with its own characteristics. Constructing a personalized city brand has always been the strategic goal pursued by most cities, especially when the competition among cities has become increasingly fierce with the continuous acceleration of China's urbanization process. However, due to the global economic integration, city brand image tends to be homogenized [1], and unvaried and toneless forms of urban buildings emerge in China. The main reason for this phenomenon is that many cities fail to fully excavate and develop their own inherent historical and cultural resources, which makes the brand image design of the whole city lack of individuality and difference. Therefore, it will be an urgent concern for the administration managers in each city to overcome this difficulty.

\section{THEORETICAL BACKGROUND}

\section{1 City Brand}

Since the concept of city brand was put forward in 1996, it has been introduced by the vast majority of cities. Generally speaking, city brand refers to the act of conveying one's own city brand to the outside world through media publicity, activity experience and other ways, in order to be different from other competing cities, excavate and integrate the inherent culture, history, environment and other resources of the city [2]. Building a city brand in line with regional characteristics is politically conducive to the government's promotion of urban development, transmission of good government spirit, and systematic management of various things in the city. Economically, each stakeholder in the city transforms the unique brand elements into derivatives with rich economic interests to expand the scale of urban economic construction. In terms of culture, city brand shows the unique memory of the city, enhances the centripetal force and popularity of the whole city, and attracts continuous visits of foreign tourists [3]. It can be seen from this that an excellent city brand can provide a clear strategic goal for the development of the whole city.

\subsection{City Brand Image Design}

In the process of building city brand strategy, there are all kinds of activities and marketing means, among which city brand image design plays an important role. It mainly refers to all the visual activities based on the history and culture of the city, in order to more intuitively show the city blueprint, brand value, image connotation and traditional history. It converts the inner tangible and intangible resources of a city into visual elements, which are specifically manifested in a series of design 
categories such as city slogans, symbols, colors, fonts, and symbolic patterns [4], to convey a personalized city brand image to citizens and tourists.

\section{EVOLVING PERIOD OF THE CITY BRAND IMAGE DESIGN IN SEOUL}

Seoul, the capital of South Korea, is a city full of youthful energy. Since the Seoul government has attached great importance to the construction of the city's brand image in the past 20 years, Seoul has become a city with wide popularity in the world. Among the factors contributing to its fame, the cultural soft power is the most prominent, which has transmitted the Korean culture to the world. Until now, the city brand image of Seoul has become a synonym of the national culture of Korea, attracting a large number of tourists from Korea and abroad to visit and experience. In order to clarify the overall development of Seoul city brand image, this paper takes time as the main line, divide the development process of city brand image in Seoul into three evolution periods, namely the germination period (1995 - 2001), growth period (2002 - 2010) and maturity period (2011 - present), and makes systematic analysis respectively.

\subsection{Germination Period (1995 - 2001)}

In 1988, the city of Seoul successfully held the 24th Summer Olympic Games, which greatly improved the image of Seoul and its international popularity. Later, in order to better integrate the overall brand image of Seoul, the Seoul Municipal Government implemented a series of "open economy" policies to promote the communication with different cultures of different countries. The first generation of the city brand image in Seoul was officially launched in 1996, as shown in "Figure 1". The red part represents the sun, which symbolizes the future and hope; the green part represents the mountains, symbolizing the love of the environment, while the blue part represents the Han River, symbolizing history and vitality. These three elements are naturally linked together, allowing people to feel the city image and culture of Seoul intimately.

\section{a) SEOUL METROPOLITAN GOVERNMENT}

Figure 1 The first generation of city brand image.
At that time, the Seoul Municipal Government combined its own cultural background and historical resources, and determined the future direction of urban brand development through integrated marketing methods. Moreover, in 2001, it established the Urban Marketing Promotion Class to cultivate a group of urban marketing and visual design talents, which laid a solid foundation for the later growth of the Seoul city brand. During this period, although Seoul realized the importance of building the city brand image, it encountered many difficulties in the implementation process. For example, the visual confusion of various administrative departments, the government's insufficient awareness of the integrity and differentiation of the city brand, and so on, all have a certain impact.

\subsection{Growth Period (2002 -2010)}

In 2002, the World Cup between Korea and Japan was held in Seoul, which attracted a large number of fans and tourists and made Seoul's brand image fly over qualitatively. At that time, the Seoul municipal government determined the development strategy of the city brand image based on Asia and looking into the world, and continued to show the citizens and tourists the perfect combination of modern and traditional culture of Seoul. In order to continue the steady development of Seoul city brand image, in August 2002, after 21 days of screening opinions solicited from the public the Seoul Municipal Government finally issued the Seoul city slogan "Hi Seoul" ("Figure 2") in October of the same year so as to make the city brand image more visible. To better publicize The slogan, The Seoul Municipal Government specially wrote the theme song "The Light of Seoul" for the slogan of "Hi Seoul" as the city song, and invited the female singer BoA, who was popular in Asia at that time, to sing it, and acted as the City Tourism Publicity Ambassador of Seoul, showing the energetic and vibrant image of Seoul.

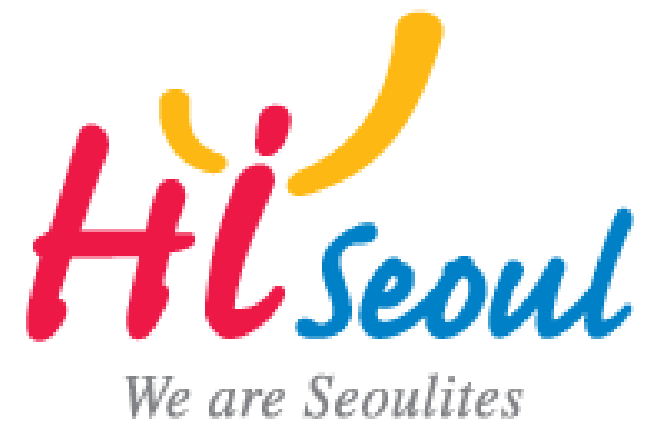

Figure 2 The second generation of city brand image. 
In 2008, the government made propaganda with the slogan "Hi Seoul/Soul of Asia", attracting 12 million foreign tourists. In 2009, in order to put the brand image apart, the government once again took "Infinitely yours, Seoul" as the brand new slogan, and printed a large number of promotional materials, including city travel guides, food guides, beauty guides and other related books, and placed them in the entry-exit department, major commercial centers and tourist attractions, making it easy for citizens and foreign tourists to read at anytime and anywhere.

\subsection{Maturity Period (2011-Present)}

Due to the aging of cities, increasing polarization and the continuous formation of a multicultural society, the need to build the "integrity" of city brands is becoming more and more urgent [5]. Since 2011, the Seoul Municipal Government has begun to prepare for the Urban Brand Development Committee, to train various urban brand management talents, and actively call on enterprises, civil society, citizens and other urban stakeholders to participate in the city brand construction, so as to provide advice for the development of long-term urban brand strategy for Seoul. Specialized organizations and departments were also set up for the integration, marketing and management of Seoul city brand. Finally, the strategic goal of developing the city brand image design with the characteristics of systematization, long-term and sustainability is determined, transmitting a positive city brand image of Seoul to the outside world through various media and experience activities. The Seoul Municipal Government has realized that only based on its own individualized culture and long historical resources, and constantly excavating and integrating these cultural elements, can it continuously show the endless personality and possibilities of Seoul to the outside world through visual design. In 2015, from the perspective of sustainability, the city of Seoul determined the development goals of the city brand with the three key words of "passion, leisure and coexistence" as the goal, and transmitted the brand image of "people" as the center of service and experience. Finally, through the participation of 200,000 citizens and experts and scholars from all walks of life, the variable visual logo "I. Seoul ·U" was finally constructed, as shown in "Figure 3". In the logo, the red dot to the right of the "I" represents enthusiasm, the letter " $U$ " to the left of the green dot on behalf of the leisure, the "O" in the word "SEOUL" represents the coexistence of SEOUL and the world, which is a symbol of the "sometimescomplex mix-and-match" philosophy.

\section{I.SEOUL·U}

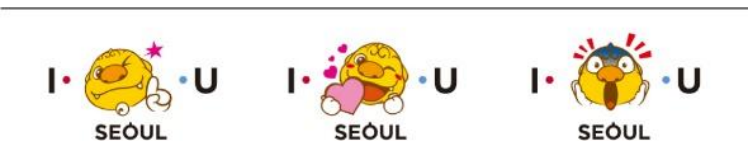

Figure 3 Third generation of city brand image.

The government made the sign available in an open form to citizens, with the word "Seoul" as a variable that can be converted into everything related to the city. At the same time, everyone can change the form of the logo according to their own characteristics and preferences, and design their own brand image and goods, reflecting the inclusive and open brand of Seoul.

\subsection{A Contrast of the Characteristics of Each Evolutionary Period}

The analysis of the three evolution periods of Seoul's urban brand image design, namely "germination period", "growth period" and "maturity period", shows that each period has distinct characteristics, as shown in "Table 1". First of all, in the germination period, Seoul took the opportunity of hosting the 24th Olympic Games, vigorously developed the city's public infrastructure, and transmitted the inherent history and culture of Seoul to the outside world through various major media, thus establishing the city brand image with Seoul characteristics for the first time. The traditional historical and cultural resources of Seoul have been integrated in succession, and a number of design talents and urban brand marketing talents have been cultivated. From a long-term perspective, this has laid a foundation for the construction of the city brand image system by the Seoul Municipal Government. At this period, the city brand image design is mainly to distinguish the visual image from other cities and highlight the characteristics of the city itself. The logo is expressed in the form of graphic implication and tends to be the design of visual image symbols. In the process of city brand image design, the Seoul Municipal Government takes the lead in the whole process. Secondly, in the growth stage, in order to develop the city brand image steadily since the $21 \mathrm{st}$ century, Seoul has set the strategic goal of building a city tourism brand. Based on the slogan "I Love NY" of New York tourism advertising, the slogan "Hi Seoul" is introduced, which highlights the friendly attitude and hospitable city image. During this period, Seoul's urban tourism income was increasing every year, and the city brand marketing model with Seoul 
characteristics transmitted its own historical and cultural characteristics to the world. The backbone of the city brand image propaganda then is the use of slogans. The city brand image is presented in the form of text, and the government is fully involved in the production of slogans. Finally, in the maturity period, after Seoul was named as the "City of Design" in 2010, in order to adapt to the information society and consolidate the city brand image of Seoul, it customized a long-term and forward-looking brand strategy model. This provides guidance for the future development of Seoul city brand with more humanization. The development of city brand image in this period paid more attention to the experience and feeling of people, centered on "people", emphasized the characteristics of openness, participation, experience and innovation of city brand design, highlighted the cultural identity and inclusiveness of city brand, and focused more on the inner experience of citizens and tourists. The city brand image design in this period allows change in the $\log 0$ form according to the different use environment, personal preference and media, which is a kind of variable logo. The design process mainly involves the participation of urban stakeholders such as the government, citizens and experts.

Table 1. The characteristics of Seoul city brand in each evolution period

\begin{tabular}{|c|c|}
\hline & $\begin{array}{l}\begin{array}{l}\text { Germination period } \\
\begin{array}{l}\text { (The first generation of city (The second generation of city } \\
\text { brand image) }\end{array} \\
\text { brand image) }\end{array} \quad \begin{array}{l}\text { Maturity period } \\
\text { brand image) }\end{array} \\
\end{array}$ \\
\hline Developmental background & 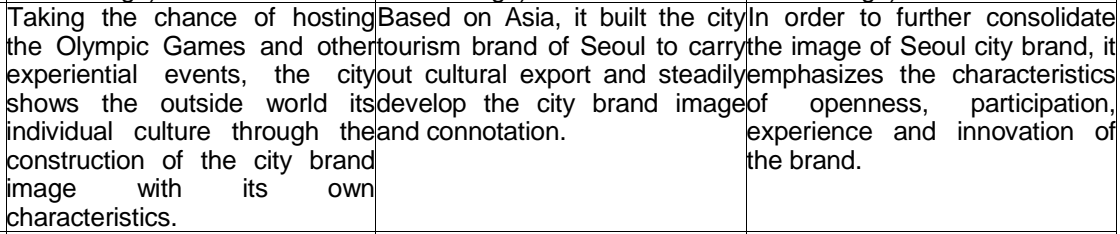 \\
\hline Goal & $\begin{array}{l}\text { cultural identity, service } \\
\text { experience }\end{array}$ \\
\hline Forms & variable type \\
\hline Characteristic & $\begin{array}{l}\text { The expression of avariable forms of signs } \\
\text { propaganda slogan }\end{array}$ \\
\hline Form of participation & $\begin{array}{l}\text { participation of the government, } \\
\text { citizens and experts, etc. }\end{array}$ \\
\hline
\end{tabular}

\section{THE INSPIRATION OF SEOUL CITY BRAND IMAGE DESIGN}

\subsection{Comprehensive Integrated Marketing of City Brand Image}

From the analysis of the characteristics of the evolution of the Seoul city brand, it is concluded that the Seoul Municipal Government has established the development goal of the city brand with "people" as the service center since the first launch of the city brand image design in 1996, until 2015. One of the most important strategic techniques is to integrate all the cultural elements and administrative resources in the region. For example, international sports events are held, a large number of city brand publicity materials are put into many departments and scenic spots, various forms of traditional cultural experience activities are carried out, and various kinds of new media are used for advertising and publicity. In a word, all the resources of the city were mined, and the integrated marketing of the city brand was carried out in an all-round way with the goal of creating an individualized brand.

\subsection{Variable Design Form of City Brand Image}

As a complex, the property of city involves many stakeholders. Therefore, it is not enough to express the city's historical and cultural connotation and government policies through a single city brand image. It can be seen from the maturity period of Seoul city brand that the Seoul Municipal Government has introduced a variable city brand image design system, which mainly generalizes the historical and cultural resources of Seoul region through various visual elements, and then presents them to the public in a variable visual form [6]. The overall visual image of the final $\log$ o is not unchangeable, but can be adjusted according to the different media environment and forms of publicity.

\section{CONCLUSION}

Since the concept of city brand was put forward in 1990, it has attracted wide attention. However, there are many factors that need to be considered in building a city brand strategy. Therefore, the construction of city brand image design system in this 
paper is a long-term and complex process. In order to meet the diversified needs of citizens and tourists, city managers need to start from the overall situation, integrity and difference, accurately position the development direction of city brand according to the changes of the times, and comprehensively integrate various historical and cultural resources of the city.

\section{AUTHORS' CONTRIBUTIONS}

This paper is independently completed by Yong Liu.

\section{REFERENCES}

[1] ZHANG Ai-peng, "Brand Image-building of Tianjin City from the Perspective of Regional Culture", Packaging Engineering, Vol.41, No.10, 2020. PP: 294-299.

[2] Song Young-Min, "The Method to Connect Public Policy to Design for the Reinforcement of City Brand", Journal of Cultural Product \& Design, No.49, 2017. PP:47-58.

[3] LIU Yang, WANG Ling, XIE Zhen, HUA Xia, "Innovative Design Method of City Brand Image", Packaging Engineering, Vol.41, No.10, 2020. PP: 235-241.

[4] Jung Soo-jin, Kim Cho-won, "A Study on the Integrative City Brand Identity Strategy", Journal of Korea Design Knowledge, No.28, 2013. PP: 297-306.

[5] Jang Hun-jong, "A study on the Seoul brand identity using the TCCS analysis model", Journal of Cultural Product \& Design, No.50, 2017. PP:63-72.

[6] Lee Ga-yun, Jung Jung-ho, "A Study on the Expression of Flexible Identity Based on the Participatory Governance of City Branding", Journal of Communication Design, Vol.63, 2018. PP: 197-212. 